
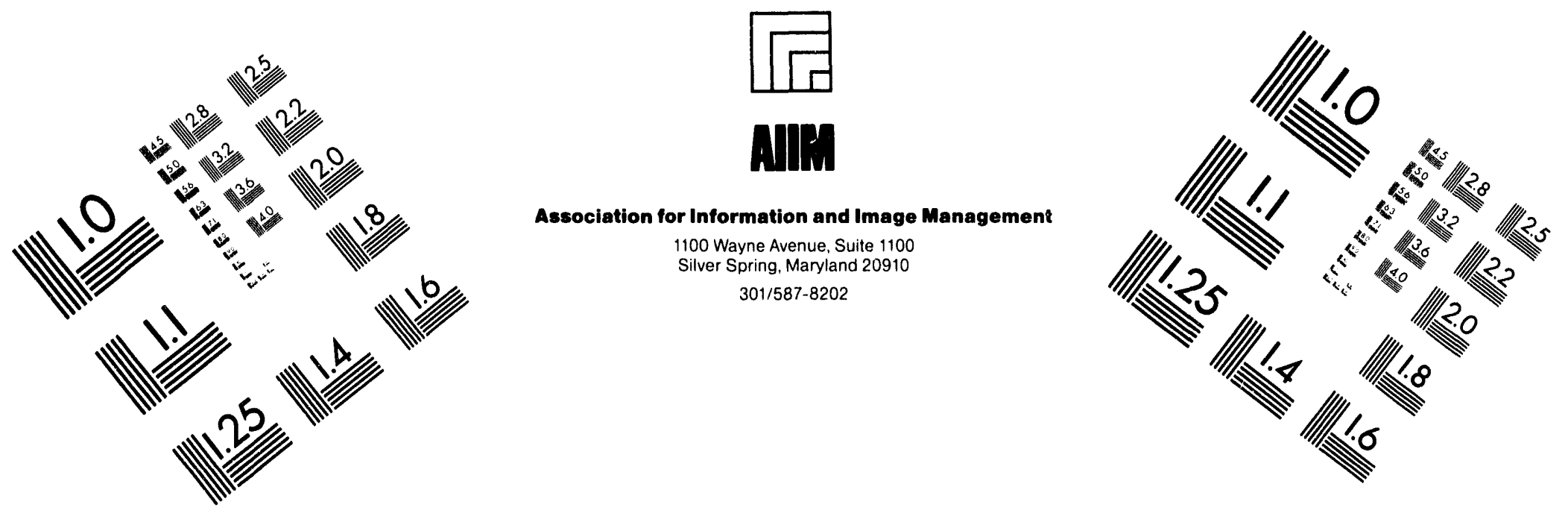

Centimeter

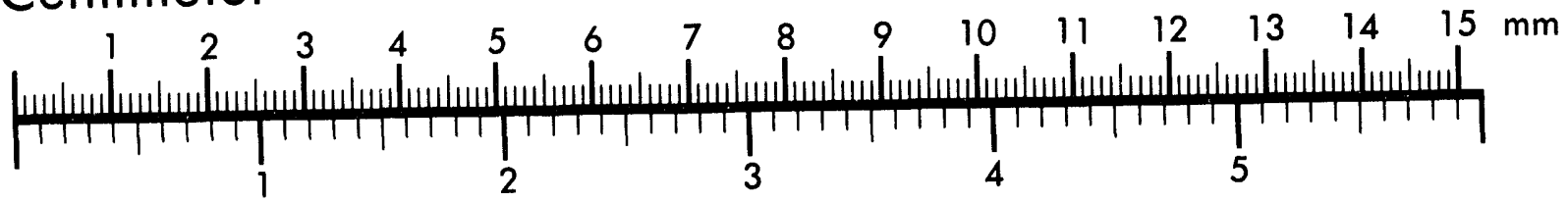
Inches
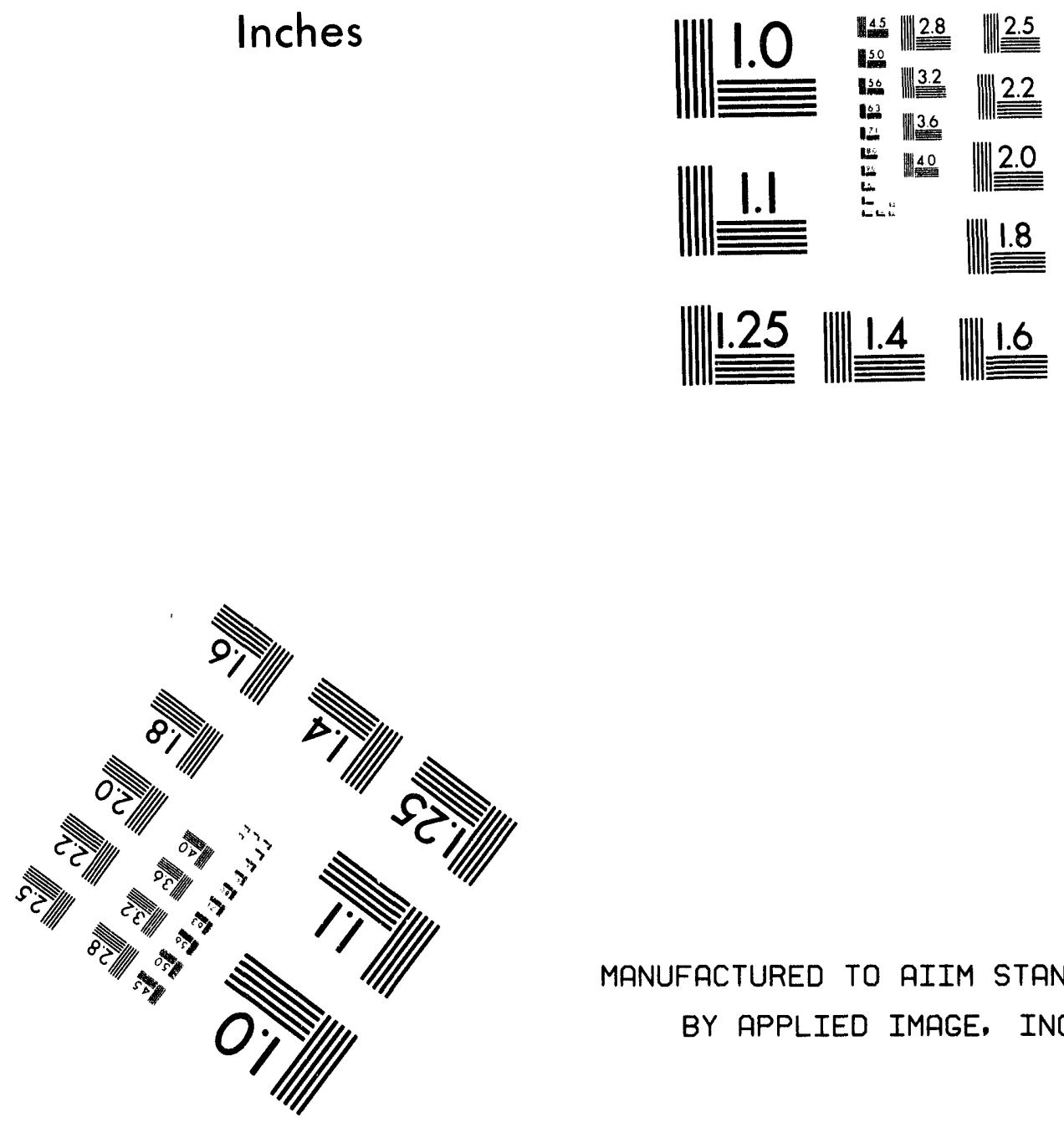

MANUFACTURED TO AIIM STANDARDS BY APPLIED IMAGE, INC.

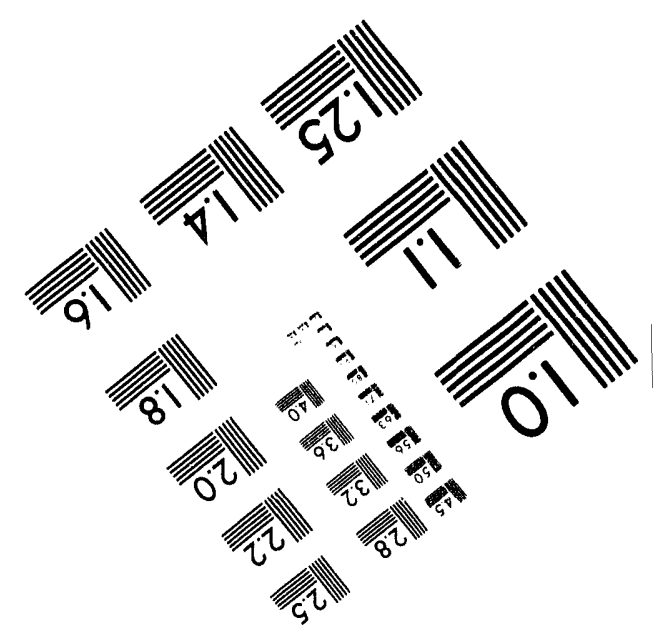



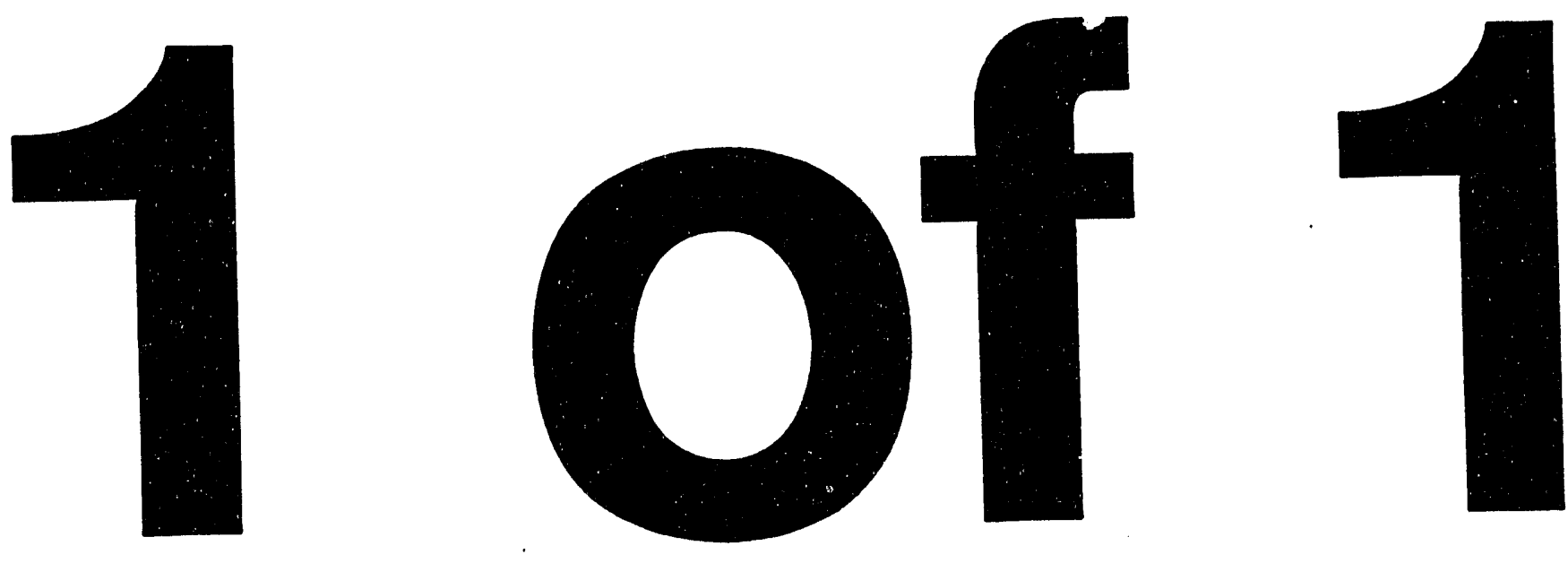


\title{
Electron Heating and Current Drive by Mode Converted Slow Waves.
}

\author{
R. Majeski, C. K. Phillips, and J. R. Wilson \\ Princeton Plasma Physics Laboratory, P.O. Box 451, Princeton, New Jersey \\ 08543
}

\begin{abstract}
An approach to obtaining efficient single pass mode conversion at high parallel wavenumber from the fast magnetosonic wave to the slow ion Bernstein wave, in a two ion species tokamak plasma, is described. The intent is to produce localized electron heating or current drive via the mode converted slow wave. In particular, this technique can be adapted to off-axis current drive for current profile control. Modelling for the case of deuterium-tritium plasmas in TFTR is presented.
\end{abstract}

PACS numbers: $52.50 . \mathrm{Gj}, 52.55 . \mathrm{Fa}$

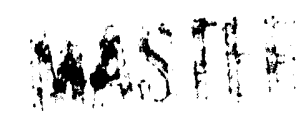




\section{Introduction.}

Mode conversion from the fast magnetosonic wave to the slow ion Bernstein wave (IBW) in a two-ion component plasma is known to play a part in ICRF (Ion Cyclotron Range of Frequency) heating schemes in tokamak plasmas. For example, mode conversion is predicted to be an important process in deuterium-tritium (D-T) plasmas, ${ }^{1}$ where the densities of the two ion species are approximately equal. In experiments with a fast wave antenna on the high field side of the torus, IBW heating of electrons dominated the power flow. 2 Mode conversion and the modification of the fast wave polarization near the ion-ion hybrid resonance is known to be important in minority ion heating, especially at low parallel wavenumber $\left(k_{\|}\right){ }^{1,3,4,5,6,7}$ Mode conversion from the fast wave to the slow Alfven wave near the high field side plasma edge can be significant in large tokamaks. 8

Most of the current generation of large tokamaks have high power long pulse ICRF systems for heating, with antennas sited on the low field side of the torus. Here we discuss a regime for efficient fast wave - IBW mode conversion in a two ion species plasma, for the purpose of direct electron heating or current drive by the IBW using existing low field side ICRF systems. For near-equal ion concentrations the mode conversion surface can be sited in the plasma core, while the ion cyclotron resonances are off axis in the colder regions of the plasma. This geometry limits fast wave ion heating. Efficient mode conversion is predicted at high $k_{\|}$for the proper choice of plasma parameters, so that the Bernstein wave phase velocity $v_{\phi}=\omega / k \|$ is on the order of or less than the electron thermal velocity VTe. Strong, localized electron damping of the Bernstein wave is expected to result. 
An examination of the cold plasma resonance and cutoff surfaces shows that for parameters typical of large present-day tokamaks, these surfaces coalesce into a closely spaced cutoff-resonance-cutoff triplet at some experimentally accessible $k\|\equiv k\| c$. The evanescent layer between the low field side cutoff arid the mode conversion surface is therefore thin for parallel wavenumbers slightly less than $k \| c$, which enhances tunnelling of the fast wave from the low field side and the mode conversion efficiency. The presence of the second cutoff on the high field side of the resonance augments the wave electric field at the mode conversion surface to further increase the mode conversion efficiency. Such effects have been discussed for the Alfven resonance $4,8,9$ but the importance of the high field side resonance in mode conversion at the ion-ion hybrid resonance has not been previously noted.

Here we model for the first time the effect of a resonance-cutoff-resonance triplet on mode conversion in the experimentally important ion-ion hybrid case. Numerical results indicate that in excess of $80 \%$ per pass of the fast wave power incident on the triplet can be mode converted and coupled directly to electrons.

Efficient, off-axis heating of thermal electrons has potential applications in MHD control, current profile control, and electron heat transport studies.

Off axis current drive is also of interest. Electron cyclotron heating could in principle provide a (proven) alternate bulk electron heating and current drive technique, but there are at present no microwave sources capable of supplying multimegawatt long pulse power at appropriate frequencies. In contrast, all of the present generation of large tokamaks have high power heating systems in the ICRF. High efficiency mode conversion therefore has the potential for wide utilization in the near term in fusion research. 
Cold plasma considerations.

For the ICRF the relevant cold plasma dispersion relation may be written: 4

$$
n_{\perp}^{2}=\frac{\left(K_{\perp}+K_{x}-n_{11}^{2}\right)\left(K_{\perp}-K_{x}-n_{\| 1}^{2}\right)}{\left(K_{\perp}-n_{1}^{2}\right)}=\frac{\left(R-n_{\mid 1}^{2}\right)\left(L-n_{\| 1}^{2}\right)}{\left(S-n_{\| 1}^{2}\right)}
$$

where

$$
K_{\perp}=1-\sum_{j} \frac{\omega_{p j}^{2}}{\omega^{2}-\Omega_{j}^{2}}, \quad K_{x}=\sum_{j} \frac{\Omega_{j}}{\omega} \frac{\omega_{p j}^{2}}{\omega^{2}-\Omega_{j}^{2}}
$$

and $n_{\perp}=c k_{\perp} / \omega, n_{\|}=c k \| / \omega, \omega j^{2}=n q^{2} /\left(m_{j} \varepsilon_{0}\right), \Omega_{j}=q_{j} B_{0} / m_{j} ; m_{j}$ and $q_{j}$ being the mass and charge of the jth species. The notation $R, L$, and $S$ follows Stix. ${ }^{4}$ Mode conversion between the fast and slow modes occurs at the $n_{\|}{ }^{2}=S$ surface when hot plasma effects are included. ${ }^{1}$ For a single ion species plasma, this surface occurs only for $\omega<\Omega i$, and is referred to as the Alfven resonance. For a plasma with two ion species an additional mode conversion surface appears at a frequency intermediate to the two ion cyclotron frequencies, and is referred to as the ion-ion hybrid resonance.

For the case of the ion-ion hybrid resonance in the situation usually considered, where $k_{\|}$is small and the fast wave is incident from the low field side, the fast wave is cutoff at the $n_{\|}^{2}=L$ surface before reaching the resonance. Here the $n_{\|}{ }^{2}=R$ cutoff surface occurs at low density far from the resonance, and so the $L$ and $S$ surfaces form an isolated cutoff-resonance pair. In this case the 
mode converted power can be shown to be given by $|T|^{2}\left(1-|T|^{2}\right)$, where $|T|=\mathrm{e}^{-\eta}$ and $\eta$ is the tunnelling factor. $5,6,10$

We consider here a two-ion hybrid resonance regime where the $n \|^{2}=L, R$, and $S$ surfaces occur in a closely spaced cutoff-resonance-cutoff triplet. Such a situation can be produced in present day large tokamaks in D-T plasmas by correctly choosing the species fraction, normalized frequency, and central density. We take TFTR as an example system. In Figure 1 a map of the locations in the equatorial plane of the cold plasma cutoffs and resonances for TFTR as a function of the parallel wavenumber are shown. The density profile was modelled as $n_{e}(r) \sim n_{e}(0)\left(1-(r / a)^{1.5}\right)^{1.5}$, appropriate to a supershot discharge, with $n_{e}(0)=5 \times 10^{19} \mathrm{~m}^{-3}$, major radius $2.62 \mathrm{~m}$, minor radius $0.98 \mathrm{~m}$, and a central toroidal field of $4.8 \mathrm{~T}$. The assumed fractional concentration of tritium was $\eta_{T} \equiv n_{T} / n_{e}=0.4$ in a deuterium plasma and the frequency, $33 \mathrm{MHz}$. The cutoffs and resonances coalesce at $R$ (major radius) $2.3 \mathrm{~m}$, or $r / a \sim 0.3$, for $k_{\|}=k_{\|} \sim 12 \mathrm{~m}^{-1}$. This wavenumber corresponds approximately to the peak in the vacuum antenna spectrum for the TFTR ICRH antennas, for $90^{\circ}$ phasing, when toroidicity $(k \| \sim 1 / R)$ is included. For $k\|<k\| c$ the ordering of the cutoffs and resonances is the same as for the familiar minority ion heating regime; for $k\|>k\| c$ the ordering is the same as for the Alfven regime 4,8 . For $k\|=k\| c a$ cutoff is produced. In practice, $k\|<k\| c$ is required for good antenna coupling at the low field side edge. Two factors favor efficient mode conversion for $k \|$ on the order of (but less than) $k \| c$ : the proximity of the $n \|^{2}=L$ cutoff and the $n \|^{2}=S$ resonance which allows efficient tunnelling through the evanescent layer, and the second cutoff at $n_{\|}^{2}=R$ which reflects transmitted fast wave power back into the resonance from the high field side.

The resonance location is primarily determined by the frequency and the relative concentration of the two ion species (deuterium and tritium here), and 
so off-axis electron heating and current drive is possible. In fast wave direct electron heating and current drive, by contrast, the inverse damping length of the fast wave on electrons $\operatorname{Im}\left(k_{\perp}\right)$ scales as $\operatorname{Re}\left(k_{\perp}\right) \beta_{e} \xi e^{-\xi^{2}}$, where $\beta_{e}$ is the electron beta and $\xi=\omega / k_{\|} v_{T e} \cdot{ }^{11}$ The linear dependence of the inverse damping length on $\beta_{e} \sim n_{e} T_{e}$ produces a power deposition profile which is always peaked on axis.

In the mode conversion case, the radial location of the power deposition can be varied with the frequency. In the limit where $n_{\|}{ }^{2} \gg 1$ but $\omega_{p i^{2}} \gg n_{\|}{ }^{2} \omega^{2}$ the location of the resonance in major radius may be approximated as

$$
R=\frac{1}{\omega} \frac{e B_{0} R_{0}}{m_{1}}\left[\frac{\omega_{p 2}^{2}+\omega_{p 1}^{2} \mu_{\mathrm{rel}}^{2}}{\omega_{p 1}^{2}+\omega_{p 2}^{2}}\right]^{1 / 2}
$$

where $R_{0}$ is the major radius of the axis, $B_{0}$ is the on-axis toroidal field, and $\mu$ rel is ratio of the ion masses. Since $R \sim 1 / \omega$ here, a $10 \%$ variation in the frequency of the coupled fast wave would be sufficient to vary the location of the resonance, and the resulting slow wave heating or current drive, by $\Delta r / a \sim 0.25$ for typical tokamak aspect ratios. Active profile control in future long-pulse tokamaks may therefore be possible.

\section{Mode conversion efficiency}

In the absence of the secondary high field side cutoff, the mode conversion efficiency is determined by the tunnelling factor, which can be approximated in plane geometry as 7,8

$$
\eta=\frac{-(\pi / 2)\left(D_{0}^{2} / S^{\prime}\right)}{\left(-\left(D^{2}\right)^{\prime} / S^{\prime}\right)^{1 / 2}}
$$


Here $D=1 / 2(R-L)$ and the subscript 0 denotes evaluation at the spatial position of the $n_{\|}{ }^{2}=S$ resonance. $S$ and $D^{2}$ have been linearized in the spatial coordinate $x$ as $S-n \|^{2}=S^{\prime} x$ and $D^{2}=D_{0}^{2}+\left(D^{2}\right)^{\prime} x$, where $x, y$, and $z$ respectively denote the radial, poloidal, and toroidal directions and are normalized to $c / \omega$.

In Fig. 2 we plot the estimate of the percentage of the mode converted power $|T|^{2}\left(1-|T|^{2}\right), \quad|T|=e^{-\eta}$, as a function of $k_{\|}$using $E q$. (3) to determine $\eta$. Plasma parameters were the same as for Fig. 1. Also shown in Fig. 2 is an estimate of the mode converted power using the fourth order 1-D full wave code CARDS. ${ }^{12}$ Here the spatial extent of the plasma slab modelled included the $n \|^{2}=L$ cutoff and $n_{\|^{2}}{ }^{2}=S$ resonance only; the high field side $n_{\|}{ }^{2}=R$ cutoff was excluded. Competing absorption mechanisms are not considered. The numerical modelling assumed a central ion temperature $T_{i}(0)=20 \mathrm{keV}$, and a central electron temperature $T_{e}(0)=10 \mathrm{keV}$, with a profile varying as $T_{i, e}(0)(1-$ $\left.(r / a)^{1.5}\right)^{2.5}$ appropriate to a supershot discharge in TFTR. For this case the analytic expression for the mode converted power and the numerical results are in excellent agreement. Both indicate that, for the isolated cutoff-resonance case there is a broad maximum in the mode conversion efficiency at $k_{\|}=8-10$ $\mathrm{m}^{-1}$; or somewhat below $\mathrm{k} \| \mathrm{c}$.

For the case of interest here, which includes the $n \|^{2}=R$ cutoff, it has been shown that the mode converted power can in general be written as

$$
P_{c}=\pi \frac{D_{0}^{2}}{S^{\prime}}\left|E_{y}\right|^{2}
$$

where $\left|E_{y}\right|$ is the $y$ (poloidal) component of the electric field at the resonance. 8 The presence of a nearby cutoff would be expected to modify the mode conversion efficiency by modifying $\left|E_{y}\right|$ at the resonance. This effect has not 
previously been included in estimates of mode conversion efficiency. Note that, unlike the case of a nearby conducting wall, $8\left|E_{y}\right|$ does not vanish at the cutoff. The result of numerical modelling with the CARDS code in which the high field side $n_{\|}{ }^{2}=R$ cutoff is included is also shown in Fig. 2. For high $k_{\|}\left(9-11.5 \mathrm{~m}^{-1}\right)$ the mode conversion efficiency is predicted to be significantly increased by the inclusion of the high field side cutoff. For this range in wavenumber the distance between the $n_{\|}{ }^{2}=R$ cutoff and the mode conversion layer is less than half the radial wavelength of the transmitted fast wave, where the proximity of the cutoff significantly increases the wavelength. The increase in the mode conversion efficiency is found to scale as $\left|E_{y} c\right| 2 /\left|E_{y}\right| 2$, where $\left|E_{y} c\right|\left(\left|E_{y}\right|\right)$ is numerically determined with (without) the high field side cutoff. The effect of a standing-wave pattern in $\left|E_{y}\right|$ due to reflection at the high field side cutoff is further evidenced by the elimination of mode conversion for $k \|=8.5 \mathrm{~m}^{-1}$. This value of the wavenumber is associated with a null in $\left|E_{y}\right|$ at the $n_{\|}{ }^{2}=S$ resonance. The full width at half maximum (FWHM) of the region in parallel wavenumber where enhanced mode conversion is obtained is larger than the FWHM of the TFTR ICRF antenna spectrum (the two-strap TFTR antennas are not optimized for current drive), but is of the same order as the predicted spectral width of antennas designed for fast wave current drive. ${ }^{13}$ Note that numerical modelling with the inclusion of the high field side cutoff for $k \|<6.75$ $\mathrm{m}^{-1}$ could not be performed due to the proximity of the tritium cyclotron resonance. Modelling with the sixth order fuli-wave 1-D code FELICE 14 shows similiar high mode conversion efficiency for these parameters.

The power deposition profile calculated using CARDS for the case discussed in relation to Figures (1; and (2) is shown in Fig. 3, where the full cutoff-resonance-cutoff is now modelled. A wavenumber of $k_{\|}=10 \mathrm{~m}^{-1}$ is assumed. Here the code boundaries include the fundamental ion cyclotror 
resonance of deuterium $10 \mathrm{~cm}$ to the low field side of the axis. Since deuterium is in effect the majority species here, there is only $10 \%$ single-pass absorption of the incident fast wave on the deuterium, despite the $20 \mathrm{keV}$ ion temperature. $20 \%$ of the incident power is reflected, with the remainder $(70 \%)$ undergoing mode conversion and absorption on the electrons at r/a 0.4 on the high-field side of the axis. The radial location of power deposition is a few $\mathrm{cm}$ to the high field side of the $n_{\|}{ }^{2}=S$ resonance. The full width at half maximum (FWHM) of the power deposition profile is $6 \mathrm{~cm}$. For this parameter regime, direct single pass absorption of the fast wave (which peaks near $x=0$ ) by electrons is negligible in comparison to the mode converted power.

Since the absorbed wave is a slow mode, single-pass absorption efficiency is less dependent on the electron temperature than in the case of direct electron heating by fast waves. Numerical results with variations of the central electron temperature from 2 to $30 \mathrm{keV}$, while keeping all other parameters constant, indicate that the mode converted power flow to electrons varies by less than $5 \%$ over this range in $\mathrm{Te}_{e}$. The power deposition profile does, however, broaden as $T_{e}$ is reduced, from a FWHM value of $5 \mathrm{~cm}$ at $T_{e}(0)=30$ $\mathrm{keV}$ to $20 \mathrm{~cm}$ at $2 \mathrm{keV}$. Direct electron damping of the fast wave, by contrast, is negligible at $2 \mathrm{keV}$ and is predicted to increase to only $4 \%$ per pass at $30 \mathrm{keV}$.

The increase in mode conversion efficiency which results from the presence of the secondary high field side cutoff is further demonstrated in Fig. 4. Figure 4 is a plot of the numerically estimated absorbed, reflected, and transmitted wave power, using CARDS, as a function of the position of the high field side boundary. The low field side (source) boundary is located at $R=3.0 \mathrm{~m}$, the $n_{\|}{ }^{2}=L$ cutoff and adjacent $n_{\|}{ }^{2}=S$ resonance are located at $R=2.35 \mathrm{~m}$, and the $n_{\|}^{2}=R$ cutoff is located at $R=2.15 \mathrm{~m}$. As the absorbing boundary is moved through the $n_{\|}{ }^{2}=L$ and $S$ surfaces the reflected power increases to 
approximately $25 \%$, and a similiar fraction of the power is mode converted and coupled to the electrons. As the $n_{\|}{ }^{2}=R$ cutoff is traversed the transmitted power drops to zero while the mode converted power absorbed on electrons increases due to the fast wave reflection from the cutoff and the resultant increased electric field at the mode conversion surface. The high mode conversion efficiency predicted by numerical modelling with the CARDS code is due to inclusion of the full resonance-cutoff-resonance triplet in the modelling region.

\section{Current drive efficiency}

For plasma parameters of interest in near-term large tokamaks the coalescence of the cutoff and resonant surfaces will occur at relatively large $k_{\|}$, and hence low $v_{\phi}$. For the example TFTR case discussed in conjunction with Fig. 3, $v_{\phi} / v T e \sim 0.5$ in the region where power is deposited on electrons, at $r / a=0.3-0.4$ on the high field side of the axis. It has been shown that for power deposition on the high field side of the axis the reduction of current drive efficiency due to trapped electron effects is minimized. 15 We estimate the driven current for the example case using the Ehst-Karney parameterization 15 for the current drive efficiency. All power is assumed to be deposited at an inverse aspect ratio $\varepsilon=0.1$. Since the single pass absorption is high, $90 \%$ of the launched fast wave power will be deposited on electrons in a few passes. For a Zeff of 2 , therefore, the driven current is estimated to be $0.07 \mathrm{~A} / \mathrm{W}$ of coupled fast wave power. Here Landau damping of the IBW is assumed to dominate. The figure of merit for current drive efficiency $\gamma \equiv\left(\bar{n}_{\mathrm{e}} R_{T} / 10^{20}\right)\left(1 / P_{\mathrm{rf}}\right)=0.06 \mathrm{~A}-\mathrm{W}^{-1} \mathrm{~m}^{-2}$.

Studies have shown that for high parallel phase velocity waves $\left(N_{\|} \equiv c k \| / \omega=0.1\right)$ the magnitude and sign of the Bernstein parallel wavenumber change as the wave propagates when poloidal field effects are included. 16 
Without resorting to a fully toroidal hot plasma treatment, we can estimate the change in $k_{\|}$due to poloidal field effects before the Bernstein wave is damped in our low phase velocity $\left(\dot{N}_{\|}=11\right)$ case using the 1-D code CARDS. At the mode conversion surface, the Bernstein wave vector lies in the direction of decreasing major radius ( $k \cong \mathbf{k}_{\mathbf{x}}$, where $\mathrm{x}$ is in the major radial direction). For nropagation exactly in the plasma midplane the parallel wavenumber is largely preserved. 16 Above or below the midplane the parallel wavenumber will undergo an up- or down-shift, depending on the sense of the rotational transform. In a poloidal magnetic field, $k \|=k \Theta(B \Theta / B)+n(B \Phi / B) /(R+r \cos \Theta), 16$ where $k_{\Theta}$ denotes the projection of the Bernstein wavenumber onto the poloidal direction, $\mathrm{B}_{\Theta}$ denotes the poloidal and $\mathrm{B}_{\Phi}$ the toroidal field, and $\Theta$ is the poloidal angle. For the case considered here, numerical modelling indicates that $90 \%$ of the power in the Bernstein wave is damped with $\mathrm{k}_{x}<200 \mathrm{~m}^{-1}$. The dispersion relation of the Bernstein wave was obtained using the CARDS code and is approximately valid, since $k_{\perp} \rho i<1$. Assuming that the mode conversion layer (at $r / a=0.4$ ) is located near the $q=2$ surface, then within $\pm 15 \mathrm{~cm}$ vertical displacement from the midplane poloidal effects will cause less than a $50 \%$ change in the IBW parallel wave number before the wave is damped. Thus for mode conversion at low phase velocity (high $k_{\|}$), in a sufficiently dense plasma for good wave focussing to occur, poloidal effects are not expected to dominate.

Finally, we note that if the mode conversion layer, and therefore the peak in the power deposition profile, is located on-axis, then the absence of trapped particle effects would increase the projected current drive efficiency to $0.17 \mathrm{~A}$ $W^{-1}$, again for TFTR parameters. Operation at low $v_{\phi} / v T e$ (high momentum input) can further increase the current drive efficiency in this case by an additional factor of $\sim 2.15$ Down shifts of the parallel wavenumber due to 
poloidal field effects may significantly modify the current drive efficiency in this case, however.

\section{Conclusions}

A regime for efficient excitation of the ion Bernstein wave via mode conversion of the fast magnetosonic wave for values of the launched wavenumber somewhat less than $k_{\| c}$, w'lere $k_{\| c}$ denotes the wavenumber at which the $n_{11}^{2}=L, R$ and $S$ surfaces coaresce, is discussed. This regime is a suitable candidate for on- or off-axis direct heating of electrons, and on- or offaxis current drive, to provide current profile control in the present generation of large tokamaks, using existing ICRF systems. Numerical modelling based ol: a deuterium-tritium ion system in TFTR indicates that single-pass absorption on electrons of $70 \%$ can be obtained in this regime with narrow $(<10 \mathrm{~cm})$ power deposition profiles. By contrast, single-pass direct electron absorption on the fast wave for the same plasma parameters is indicated to be weak $(<5 \%)$. The mode converted Bernstein wave is damped on thermal electrons, with $v_{\phi} \sim v T e$. Trapped electron effects are minimized by localizing the power deposition to the high field side of the magnetic axis, however. Predicted off-axis current drive efficiency is approximately $0.07 \mathrm{AW}^{-1}$ for typical TFTR parameters.

\section{Acknowledgments}

The authors acknowledge many useful conversations and comparisons of numerical results with E. F. Jaeger. CARDS was developed by D. Smithe, while the FELICE code was developed by M. Brambilla. Indispensible instruction in the operation of FELICE, as well as other valuable advice, was 
obtained from P. Bonoli. A. Bers, R. Hawryluk, J. Hosea, and M. Murakami all provided useful insight. This work was supported by U. S. Department of Energy Contract DE-AC02-76-CHO-3073. 


\section{References}

1. F. W. Perkins, Nucl. Fusion 17, 1197 (1977).

2. Equipe TFR, in Plasma physics and Controlled Nuclear Fusion Research 1982, Proc. 9th Conference, Baltimore, 1982 (IAEA, Vienna, 1983) Vol. II, p. 17.

3. M. Brambilla and T. Krucken, Nucl. Fusion 28, 1813 (1988).

4. T. H. Stix, Waves in Plasmas, American Institute of Physics, New York (1992)

5. D. G. Swanson, Phys. Fluids 28, 2645 (1985).

6. V. Fuchs and A. Bers, Phys. Fluids 31,3702 (1988).

7. J. Jacquinot, B. D. McVey, and J. E. Scharer, Phys. Rev. Lett. 39 , 88 (1977).

8. J. A. Heikkinen, T. Hellsten, M. J. Alava, Nucl. Fusion 31, 417 (1991).

9. C. F. F. Karney, F. W. Perkins, and Y. -C. Sun, Phys. Rev. Lett. 42, 1621 (1979).

10. M. J. Alava and J. A. Heikkinen, Physica Scripta 45, 345 (1992). 
11. M. Porkolab, in Radio Frequency Power in Plasmas, Proceediny, Ninth Topical Conference, Charleston,1991 (American Institute of Physics Conference Proceedings 244, New York, 1991) p. 197.

12. D. N. Smithe, Ph.D. thesis, University of Michigan, 1987.

13. D. W. Swain, et al., in Radio Frequency Power in Plasmas, Proceedings TenthTopical Conference, Boston,1993 (American Institute of Physics Conference Proceedings 289, New York, 1994) p. 371.

14. M. Brambilla, Nucl. Fusion $\underline{28}, 549$ (1988).

15. D. A. Ehst and C. F. F. Karney, Nucl Fusion 31, 1933 (1991).

16. A. K. Ram and A. Bers, Phys. Fluids B 33, 1059 (1991). 
Figure Captions.

Figure 1. Map of the cold plasma cutoff and resonant surfaces in $k_{\|}$and major

radius for TFTR. $L$ denotes the $n_{\|}{ }^{2}=L$ cutoff, $S$ denotes the $n_{\|}{ }^{2}=S$ resonance, and $R$ denotes the $n \|^{2}=R$ low density cutoff. The locations of the fundamental cyclotron resonances of deuterium and tritium are indicated by $\Omega \mathrm{D}$ and $\Omega \mathrm{T}$.

Figure 2. Estimates of the percentage of the incident power which is mode converted. The solid line denotes the analytic estimate obtained using Eq. 3 to determine $\eta$ for the isolated cutoff-resonance case. The crosses indicate the numerical results obtained with the 1-D code CARDS for the same case. The triangles indicate the numerical results for the mode converted power fraction when the additional high field side cutoff is included.

Figure 3. Power deposition profiles computed with CARDS. Electron absorption is indicated by $E$, deuterium absorption by $D$, and tritium absorption (which is negligible throughout the modelled region) by $T$. The plasma axis is at $2.62 \mathrm{~m}$.

Figure 4. Absorbed, reflected, and transmitted power as a function of the spatial position of the high field side boundary of the modelled region. Here $E$ denotes power absorbed on electrons, $D$ indicates deuterium absorption, $R$ indicates reflected power, and T denotes the power transmitted to the boundary. 


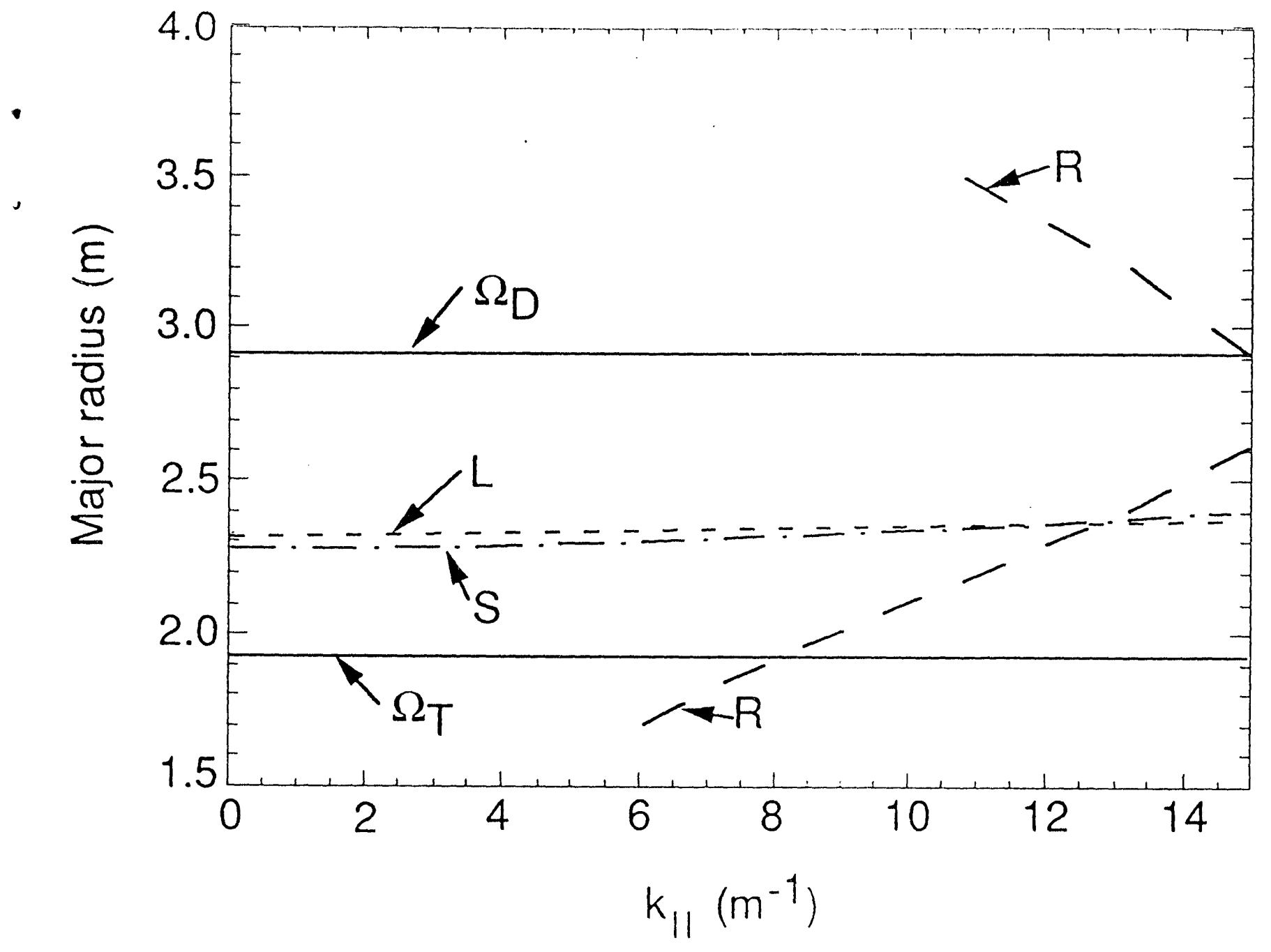

Figure 1 


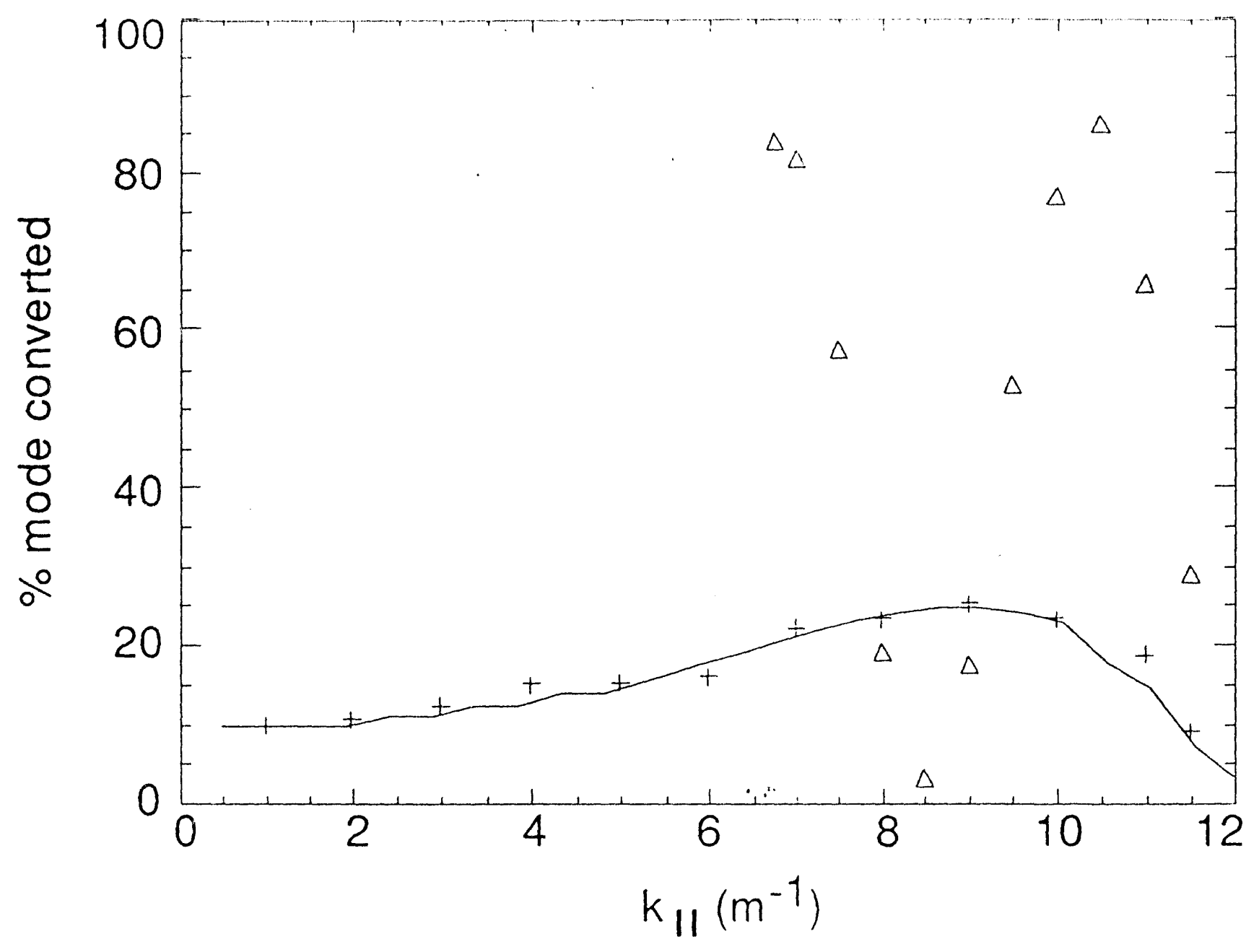

Figure 2 


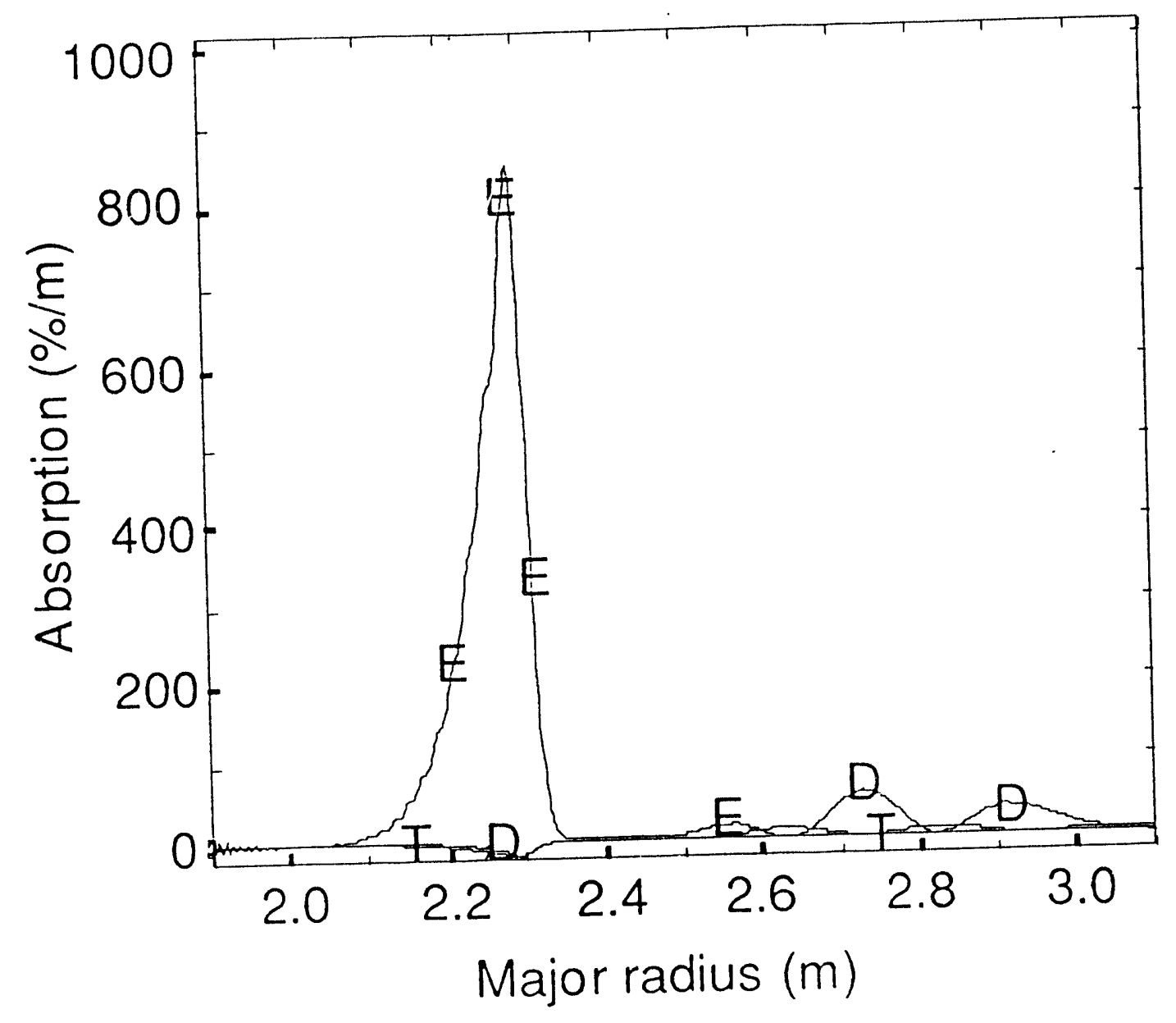

Figure 3 


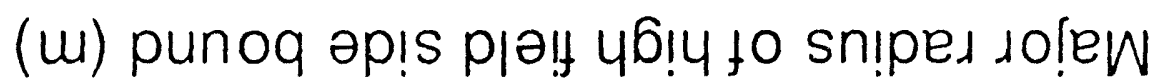

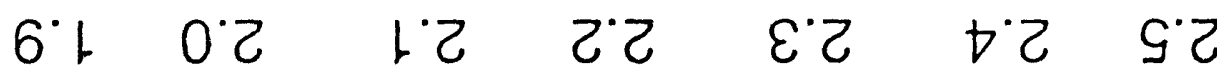

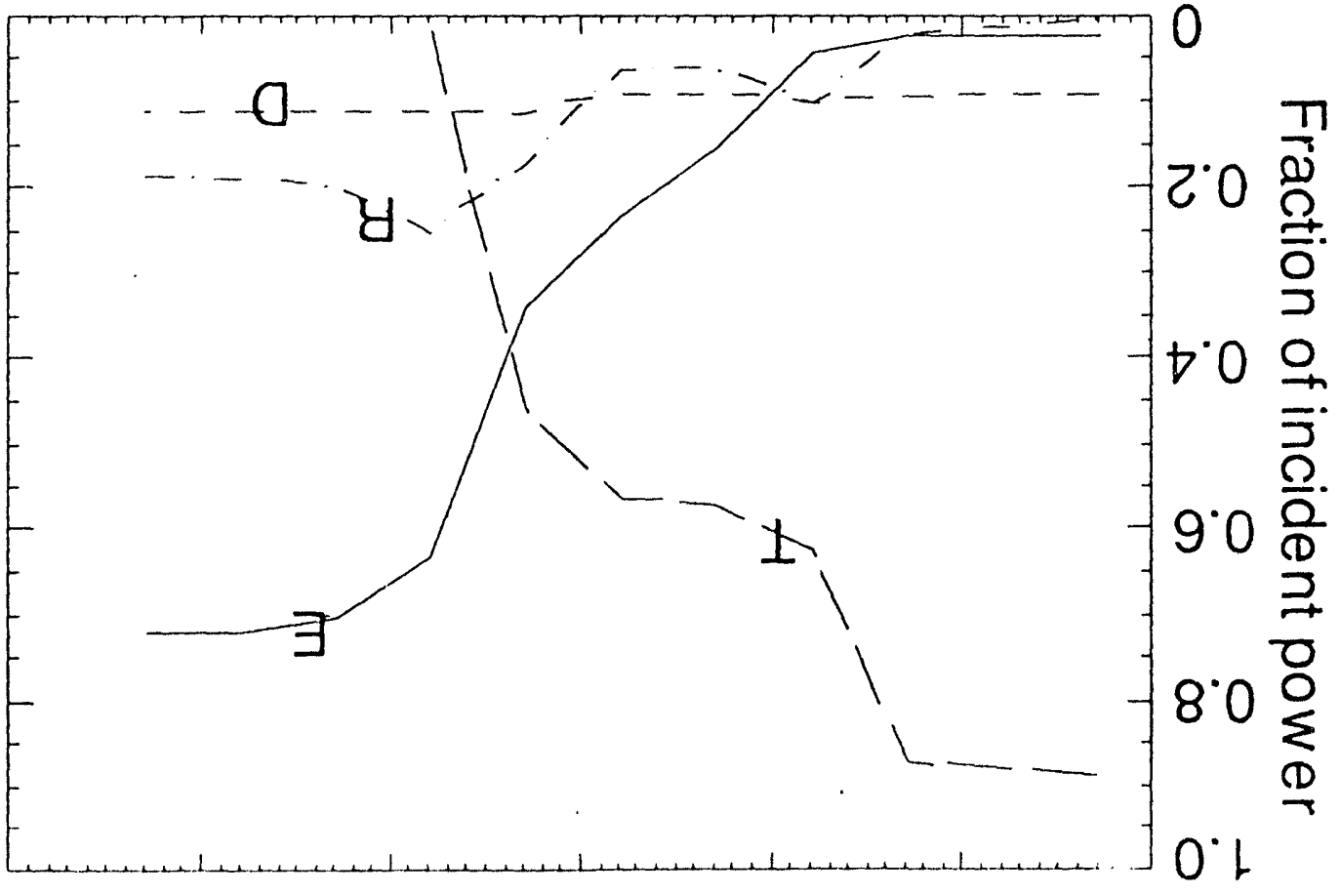




\section{EXTERNAL DISTRIBUTION IN ADDITION TO UC-420}

Dr. F. Paoloni, Univ. of Wollongong, AUSTRALIA

Prof. R.C. Cross, Univ. of Sydney, AUSTRALIA

Plasma Research Lab., Australian Nat. Univ., AUSTRALIA

Prof. I.R. Jones, Flinders Univ, AUSTRALIA

Prof. F. Cap, Inst. for Theoretical Physics, AUSTRIA

Prof. M. Heindler, Institut fur Theoretische Physik, AUSTRIA

Prof. M. Goossens, Astronomisch InstituUt, BELGIUM

Ecole Royale Militaire, Lab. de Phy. Plasmas, BELGIUM

Commission-European, DG. XII-Fusion Prog., BELGIUM

Prof. R. Bouciqué, Rijksuniversiteit Gent, BELGIUM

Dr. P.H. Sakanaka, Instituto Fisica, BRAZIL.

Prof. Dr. I.C. Nascimento, Instituto Fisica, Sao Paulo, BRAZIL Instituto Nacional De Pesquisas Espaciais-INPE, BRAZIL Documents Office, Atomic Energy of Canada Lid., CANADA Ms. M. Morin, CCFMTokamak de Varennes, CANADA Dr. M.P. Bachynski, MPB Technologies, Inc., CANADA Dr. H.M. Skarsgard, Univ. of Saskatchewan, CANADA Prof. J. Teichmann, Univ. of Montreal, CANADA Prof. S.R. Sreenivasan, Univ. of Calgary, CANADA Prof. T.W. Johnston, INRS-Energie, CANADA

Dr. R. Bolton, Centre canadien de fusion magnétique, CANADA

Dr. C.R. James,. Univ. of Alberta, CANADA

Dr. P. Lukác, Komenského Universzita, CZECHO-SLOVAKIA

The Librarian, Culham Laboratory, ENGLAND

Library, R61, Rutherford Appleton Laboratory, ENGLAND

Mrs. S.A. Hutchinson, JET Library, ENGLAND

Dr. S.C. Sharma, Univ. of South Pacific, FIJI ISLANDS

P. Măhönen, Univ. of Helsinki, FINLAND

Prof. M.N. Bussac, Ecole Polytochnique., FRANCE

C. Mouttet, Lab. de Physique des Milieux lonisés, FRANCE

J. Radet, CEN/CADARACHE - Bat 506, FRANCE

Prof. E. Economou, Univ. of Crete, GREECE

Ms. C. Rinni, Univ. of loannina, GREECE

Preprint Library, Hungarian Academy of Sci., HUNGARY

Dr. B. DasGupta, Saha Inst. of Nuclear Physics, INDIA

Dr. P. Kaw, Inst. for Plasma Research, INDIA

Dr. P. Rosenau, Israel Inst. of Technology, ISRAEL

Librarian, Intemational Center for Theo Physics, ITALY

Miss C. Do Palo, Associazione EURATOM-ENEA , ITALY

Dr. G. Grosso, Istituto di Fisica dol Plasma, ITALY

Prof. G. Rostungni, Istituto Gas Ionizzati Del Cnr, ITALY
Dr. H. Yamato, Toshiba Res \& Devel Center, JAPAN

Prof. I. Kawakami, Hiroshima Univ., JAPAN

Prof. K. Nishikawa, Hiroshima Univ., JAPAN

Librarian, Naka Fusion Research Establishment, JAERI, JAPAN

Director, Japan Atomic Energy Research Inst., JAPAN

Prot. S. Itoh, Kyushu Unix., JAPAN

Research Info. Ctr., National Instit. for Fusion Scienco, JAPAN

Prof. S. Tanaka, Kyoto Univ., JAPAN

Library, Kyoto Univ., JAPAN

Prof. N. Inove, Univ. of Tokyo, JAPAN

Secretary, Plasma Section, Electrotechnical Lab., JAPAN

Dr. O. Mitarai, Kumamoto Inst. of Tochnology, JAPAN

Dr. G.S. Lee, Korea Basic Sci. Cr., KOREA

J. Hyeon-Sook, Korea Atomic Energy Research Inst., KOREA

D.I. Choi, The Korea Adv. Inst. of Sa. Tech., KOREA

Prof. B.S. Liley, Univ. of Waikato, NEW ZEALAND

Inst of Physics, Chinese Acad Sci PEOPLE'S REP. OF CHINA Library, Inst. of Plasma Physics, PEOPLE'S REP. OF CHINA Tsinghua Univ. Library, PEOPLE'S REPUBLIC OF CHINA Z. Li, S.W. Inst Physics, PEOPLE'S REPUBLIC OF CHINA Prof. J.A.C. Cabral, Instituto Superior Tecnico, PORTUGAL Prof. M.A. Hellberg, Univ. of Natal, S. AFRICA

Prof. D.E. Kim, Pohang Inst. of Sci. \& Tech., SO. KOREA Prof. C.I.E.M.A.T, Fusion Division Library, SPAIN

Dr. L. Stenflo, Univ. of UMEA, SWEDEN

Library, Royal Inst. of Technology, SWEDEN

Prot. H. Withelmson, Chalmers Univ. of Tech., SWEDEN Centre Phys. Des Plasmas, Ecole Polytech, SWITZERLAND Bibliotheek, Inst. Voor Plasma-Fysica, THE NETHERLANDS Asst. Prof. Dr. S. Cakir, Middle East Tech. Univ., TURKEY Dr. V.A. Glukhikh,Sci. Res. Inst. Electrophys.I Apparatus, USSR Dr. D.D. Ryutov, Siberian Branch of Academy of Sci., USSR Dr. G.A. Eliseov, I.V. Kurchatov Inst., USSA Librarian, The Ukr.SSR Academy of Sciences, USSR Dr. L.M. Kovrizhnykh, Inst. of General Physics, USSR Kemforschungsanlage GmbH, Zentralbibliothek, W. GERMANY Bibliothek, Inst. For Plasmatorschung, W. GERMANY Prof. K. Schindler, Ruhr-Universitét Bochum, W. GERMANY Dr. F. Wagner, (ASDEX), Max-Planck-Institut, W. GERMANY Librarian, Max-Planck-Institut, W. GERMANY 

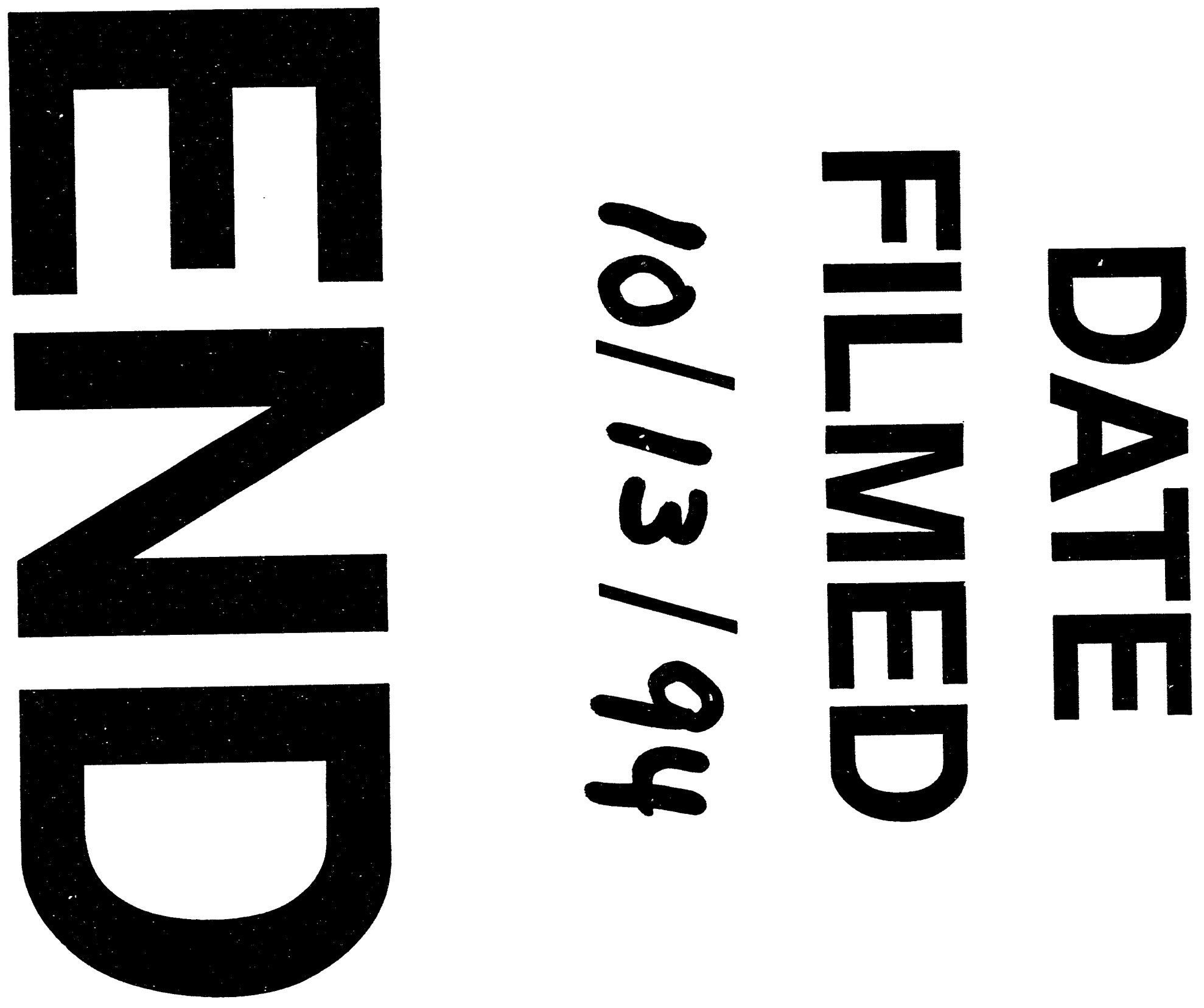


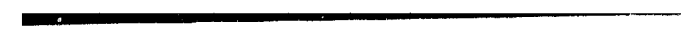

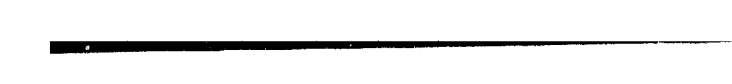

$\mid$
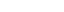